Juraj Sprung MD PhD, J. David Haddox DDS MD, Anita M. Maitra-D'Cruze MD

\title{
Horner's syndrome and trigeminal nerve palsy following epidural anaesthesia for obstetrics
}

\begin{abstract}
While Horner's syndrome is a rare but occasionally reported side-effect of epidural block administered for labour, trigeminal nerve palsy has been described only ance. The cases described in this report confirmed the benign nature of these neurological complications of epidurally administered anaestherics which were not detrimental to fetal viability. The complications may be attributed to extensive cephalad spread of local anaesthetic, sometimes via unexplained routes and with surprisingly selective targeting effect (unilateral trigeminal nerve palsy). The atypical and unusually high cephalad spread of local anaesthetic in pregnant women at term is believed to be due 10 pregnancy-related altered anatomy and physiology of the epidural space.
\end{abstract}

Alors que le syndrome de Horner est rare mais occasionnellement rapporté comme un effet secondaire du bloc épidural administré lors de l'accouchement, la paralysie du nerf trijumeau fut décrite une seule fois uniquement. Les cas rapportés dans cette revue confirme la nature bénigne de ces complications neurologiques après administration épidurale d'anesthésiques sans effet néfaste sur la viabilité foetale. Les complications peuvent être attribuées à l'extension de l'anesthésique local quelquefois à travers des routes inexpliquées et avec une sensibilité sélective surprenante (paralysie du nerf trijumeau unilatéral). L'extension céphalique atypique et habituelle de

\section{Key words}

ANAESTHESIA: obstetrical;

SURGERY: Caesarean section;

COMPLICATIONS: neurological;

SYMPATHETIC NERVOUS SYSTEM: Homer's syndrome.

From the Department of Anesthesiology, Medical College of Wisconsin, Milwaukee, Wisconsin, 53226.

Address correspondence 10: Dr. Juraj Sprung, Medical

College of Wisconsin, Department of Anesthesiology, $8700 \mathrm{~W}$.

Wisconsin Avenue, Box 150, Milwaukee, WI 53226.

Accepted for publication 25th March, 1991. l'anesthésique local chez les femmes enceintes a terme est attribuée d l'altération de l'anatomie et la physiologie de l'espace épidural lors de la grossesse.

Horner's syndrome is a rare side-effect of lumbar epidural block, ${ }^{1,2}$ and was first reported by Kepes in $1972 .^{3}$ There is a high association between epidural analgesia for labour and Horner's syndrome and only one report described its occurrence after lumbar epidural block performed for treatment of chronic pain. ${ }^{4}$ An association between the occurrence of Horner's syndrome and the dose of peridurally injected local anaesthetic has not been established and Horner's syndrome has been described with a dose of local anaesthetic insufficient to produce sensory analgesia. ${ }^{1,4}$

We report two cases of Homer's syndrome which are unusual in two respects. In the first, it appeared with a low sympathetic block $\left(\mathrm{T}_{8}\right.$ level) which makes it difficult to explain paralysis of the dilator pupillae muscle. In the second case, Horner's syndrome was associated with partial paralysis of the brachial plexus (ulnar nerve) and the trigeminal nerve. We speculate that the mechanism of this rare neurological complication was related to the cephalad spread of local anaesthetic solution from the epidural to subarachnoid space and that selective trigeminal nerve palsy occurred due to local anaesthetic action on motor fibres at the level of pontine cistern.

\section{Case reports}

Case \# I

A 30-yr-old, healthy primigravida (ASA physical status I) weighing $60 \mathrm{~kg}$ and $177 \mathrm{~cm}$ tall was admitted in labour. The patient requested epidural analgesia. After hydration with $1000 \mathrm{ml}$ of lactated Ringer's solution, the patient was put in the sitting position and an 18-gauge blunt-end epidural catheter was placed without difficulty via a 17-gauge Tuohy needle through the $\mathrm{L}_{2}-\mathrm{L}_{3}$ interspace. The catheter was advanced $3 \mathrm{~cm}$ in the epidural space with the 
needle bevel pointing cephalad. A test dose of $3 \mathrm{ml} 2 \%$ lidocaine $(60 \mathrm{mg})$ ruled out intrathecal catheter position. Five milliliters of $0.25 \%$ bupivicaine were then given and did not produce adequate sensory blockade. Fifteen minutes later, two further doses of 5 and $4 \mathrm{ml}$ respectively were administered ten minutes apart. This resulted in an asymmetric block, with a level of $T_{8}$ on the right side and $T_{12}$ on the left by alcohol sponge test. ${ }^{5}$ The patient was placed in the left lateral decubitus position and a continuous infusion of $0.125 \%$ bupivicaine was started at the rate of $10 \mathrm{ml} \cdot \mathrm{hr}^{-1}$. Half an hour later the patient still complained of inadequate left-sided analgesia during uterine contractions, as well as a "funny feeling on the right side of my face and in my right eye." Examination revealed an unchanged level of anaesthesia (right- $\mathrm{T}_{8}$, left- $\left.T_{1} 2\right)$, and a right-sided Horner's syndrome. The facial skin was dry and flushed, the conjunctiva was red, the patient had difficulty breathing through the right nares, and miosis and ptosis of the eyelid were present. The patient's blood pressure (BP) was $115 / 75 \mathrm{mmHg}$, which was not different from the value prior to epidural analgesia. In spite of the development of Horner's syndrome an additional $7 \mathrm{ml}$ of $0.25 \%$ bupivicaine were administered after withdrawing the catheter $1 \mathrm{~cm}$. Good sensory block to $T_{3}$ on the right side and $10 T_{10}$ on the left resulted in satisfactory analgesia for labour. The Homer's syndrome resolved approximately three hours after its onset in spite of two subsequent $5 \mathrm{ml}$ epidural doses of $0.25 \%$ bupivicaine. A healthy infant was delivered vaginally $11 \mathrm{hr}$ after epidural block was established.

\section{Case \#2}

This patient was a 25-yr-old (ASA physical status II) who weighed $68 \mathrm{~kg}$ and was $157 \mathrm{~cm}$ tall. Her past medical history was positive for migraine headaches. She was a primigravida adnitted in labour with known breech presentation. The attending obstetrician decided to perform a Caesarean section. Epidural anaesthesia was established in an identical manner as in Case \# 1 . After an uneventful test dose of $3 \mathrm{ml} 2 \%$ lidocaine $(60 \mathrm{mg})$ with 1:200,000 epinephrine, $15 \mathrm{ml}$ of $3 \%$ 2-chloroprocaine were administered through the epidural catheter and this was associated with a gradual onset of sensory anaesthesia to $\mathrm{C}_{8}$ on the left and to $\mathrm{T}_{2}$ on the right. Her BP decreased from $115 / 60 \mathrm{mmHg}$ to $90 / 55 \mathrm{mmHg}$. The patient developed bilateral Horner's syndrome with paraesthesiae and numbness of the left side of the face in the distribution of the maxillary and mandibular divisions of the trigeminal nerve. Inability to open the mouth widely signified weakness of the motor fibres of the third division of the trigeminal nerve. In addition, weakness of the left arm and loss of sensation to touch in the distribution of the ulnar nerve $\left(C_{8}\right.$ dermatome) were present. The patient complained of mild dyspnoea, but had no change in her level of consciousness. She also complained of a mild vascular headache on her left side and felt a throbbing pain in her left mandibular teeth. A healthy infant was delivered via a Pfannenstiel approach. Three and a half hours after the onset of symptoms, the signs of Horner's syndrome, the headache, dental pain and the trigeminal palsy resolved.

\section{Discussion}

The overall reported incidence of Horner's syndrome after lumbar labour epidural block ranges from $0.5 \%-$ $4 \%$. $^{1,2,6}$ Almost all reported cases of Horner's syndrome after lumbar or caudal epidural blocks have been described in pregnant women during administration of labour epidural analgesia or epidural anaesthesia for Caesarean section (Table I). Only one was a complication of pain therapy. ${ }^{4}$ On several occasions Horner's syndrome was described with a low level of sensory blockade ${ }^{3,7-10}$ or even without any clinically detectable sensory blockade. ${ }^{4}$ In our first case, Horner's syndrome manifested with sensory analgesia to the $T_{8}$ level, which was too low to explain it by the conventionally accepted anatomical distribution of sympathetic fibres to the eye. Mohan and Potter described Horner's syndrome in three patients after administering only $2 \mathrm{ml}$ of local anaesthetic, in the absence of detectable analgesia over the trunk. ${ }^{1}$ This phenomenon may be explained on the basis of subdural spread of local anaesthetic from the epidural space" causing differential blockade of preganglionic sympathetic B-fibres without sensory blockade of Cnociceptors. Horner's syndrome manifests when the sympathetic supply to the meridional fibres of the iris, levator palpebrae, conjunctiva and face is interrupted. The nerve supply for these regions arises from the intermediolateral grey column of $C_{8}$ through $T_{1}$. Ray and Hinsey found a substantial individual variability in innervation of the dilating fibres of the iris, and the sympathetic innervation controlling the pupillary opening of the eye has been shown to travel through one or more spinal roots between the levels of $C_{8}$ and $T_{4} \cdot{ }^{12}$ In two out of ten cases they showed that stimulation of anterior spinal roots between $T_{1}$ and $T_{4}$ induced dilation of the homolateral pupil. These fibres, after passing through the white ramii communicantes, continue to the cervical sympathetic chain and ascend through the stellate and middle cervical ganglia to terminate in the superior cervical ganglion. Unmyelinated fibres leave this ganglion and form the internal carotid plexus which further divides giving rise to the cavemous plexus. Fibres from this plexus enter the orbit and send branches to the superior rectus and the levator palpebrae superioris muscles. Some fibres innervate the dilator pupillae through the long 
TABLE I Characteristics of the reported cases of Horner's syndrome after lumbar or caudal epidural blocks

\begin{tabular}{|c|c|c|c|c|c|}
\hline Case & Agent(s) & $\begin{array}{l}\text { Total volume } \\
\text { of anaesthetic } \\
(\mathrm{ml})\end{array}$ & $\begin{array}{l}\text { Purpose and } \\
\text { site of injection, } \\
\text { level of block }\end{array}$ & $\begin{array}{l}\text { Side \& duration } \\
\text { of } H S\end{array}$ & Author \& ref \\
\hline 1 & $0.75 \% \mathrm{~B}$ & 14 & $\mathrm{CS}, \mathrm{L}_{3-4}, \mathrm{C}_{6}$ & RI, 16 hrs & Ough et al. ${ }^{20}$ \\
\hline 2 & $3 \% \mathrm{CP}$ & 22 & LE, Cd, $\mathrm{T}_{4}$ & $\mathrm{Ll}_{1}<\mathrm{I} \mathrm{hr}$ & Kepes et al. ${ }^{3}$ \\
\hline 3 & $0.5 \% \mathrm{~B}$ & 27 & LE, $L_{2 \cdot 3}, T_{1}$ & $\mathrm{LI},>5 \mathrm{hrs}$ & Evans et al. ${ }^{16}$ \\
\hline 4 & $0.5 \% \mathrm{~B}$ & 22 & LE, $L_{1-2}, T_{1}$ & $\mathrm{Rt}, 5 \mathrm{hrs}$ & Evans ef al. ${ }^{16}$ \\
\hline \multirow[t]{2}{*}{5} & $0.25 \% \mathrm{~B}$ & 24 & LE, $L_{2-3}$, Upper $T$ & $\mathrm{Lt}, 6 \mathrm{hrs}$ & \\
\hline & $+0.5 \% \mathrm{~B}$ & 4 & & & Adam et al..$^{14}$ \\
\hline 6 & $0.5 \% \mathrm{~B}$ & 18 & PTx, $L_{3-4}, C_{4.5}$ & $\mathrm{R} 1,20 \mathrm{~min}$ & Shigematsu ${ }^{4}$ \\
\hline \multirow[t]{3}{*}{7} & $2 \% \mathrm{CP}$ & 6 & LE, $L_{3.4}, T_{10}$ & & \\
\hline & $+0.375 \% \mathrm{~B}$ & 5 & $L_{3-4}, T_{9}$ & & \\
\hline & $+3 \% \mathrm{CP}$ & 8 & $\mathrm{~L}_{3-4}, \mathrm{~T}_{9}$ & $\mathrm{Lt}, 17 \mathrm{~min}$ & Hertz et al.? \\
\hline 8 & $3 \% \mathrm{CP}$ & 23 & $\mathrm{CS}, \mathrm{L}_{2-3}, \mathrm{C}_{7}$ & $\mathrm{Lt}, 30 \mathrm{~min}$ & Skaredoff et al. ${ }^{8}$ \\
\hline 9 & $0.25 \% \mathrm{~B}$ & 10 & LE, $L_{2 \cdot 3}, T_{7}$ & $\mathrm{Lt}, 5 \mathrm{hrs}$ & Schackner et al.9 \\
\hline 10 & $0.5 \% \mathrm{~B}$ & 8 & LE, L, $T_{12}$ & Rt, 4 hrs & Sprigge et al. ${ }^{10}$ \\
\hline 11 & $2 \% \mathrm{CP}$ & 8 & LE, L, T, & Bilat, 3 hrs & Abboud er al. ${ }^{21}$ \\
\hline 12 & $0.25 \% \mathrm{~B}$ & 14 & LE, $L_{2-3}, T_{8}$ & $\mathrm{Rt},>3 \mathrm{hrs}$ & Sprung et al.-here \\
\hline 13 & $3 \% \mathrm{CP}$ & 15 & CS, $\mathrm{L}_{2-3}, \mathrm{C}_{8}-\mathrm{Lt}, \mathrm{T}_{2}-\mathrm{Rt}$ & Bilat, 3 hrs & Sprung et al. -here \\
\hline
\end{tabular}

*(Modified after Ough YD et al. ${ }^{17}$ )

Legend: $B=$ bupivicaine, $C P=2$-chloroprocaine; $L E=$ labour epidural; $C S=$ Caesarean section;

PTX = pain treatment; $C=$ cervical; $T=$ thoracic $C=$ lumbar; $C d=$ caudal LI $=$ left; $R t=$ right;

HS = Homer's syndrome.

ciliary nerves. Paralysis of these various sympathetic pathways causes unopposed parasympathetic tone and results in miosis, ptosis and enophthalmos.

The occurrence of Horner's syndrome in the absence of sensory blockade may be explained by the high sensitivity of sympathetic nerve fibres to local anaesthetics. ${ }^{13}$ Equally or even more important is the existence of anatomical conditions, resulting from the physiology of pregnancy and labour, such as the "space occupying ... effect of the distended extradural veins," " which will favour cranial spread of local anaesthetics. Horner's syndrome is thus a confirmatory sign of high cephalad spread of anaesthetic agent. Horner's syndrome has never been described in conjunction with more serious epidural anaesthetic complications (Table II), however, and is rarely reported to be related to transient hypotension which may be detrimental to the fetus. ${ }^{3}$ This is consistent with the postulated high sensitivity of sympathetic fibres to local anaesthetic solutions. Horner's syndrome is an isolated benign phenomenon even in situations in which, in order to achieve adequate sensory anaesthesia, additional doses of anaesthetic are needed. The fact that this phenomenon generally occurs unilaterally could indicate an asymmetric position of the catheter in the peridural space in combination with the specific body positioning during the first stage of labour or anatomical changes of the peridural space of pregnant women. Adam et al. performed postpartum epidurography in a patient who developed Horner's syndrome during delivery, and they
TABLE II Complications from epidural blocks described with development of Horner's syndrome

\begin{tabular}{|c|c|}
\hline Author & Complication \\
\hline 1 Ough $^{20}$ & $\begin{array}{l}\text { Numbness and motor weakness of the } \mathrm{n} \text { upper } \\
\text { extremity }\end{array}$ \\
\hline 2 Kepes $^{3}$ & $\begin{array}{l}\text { Decrease of BP from } 110 / 80 \text { to } 80 / 60 \mathrm{mmHg} \text { with } \\
\text { fetal bradycardia }\end{array}$ \\
\hline 3 Evans $^{14}$ & Decrease of systolic BP from $1101080 \mathrm{mmHg}$ \\
\hline 5 Shigematsu $^{4}$ & $\begin{array}{l}\text { Analgesia not achieved, paraesthesias } C_{4.5} \pi \text { arm, } \\
\text { trigeminal n. palsy }\end{array}$ \\
\hline 6 Schackner ${ }^{9}$ & $\begin{array}{l}\text { Decrease of systolic BP from } 140 \text { to } 90 \mathrm{mmHg} \\
\text { (no fetal bradycardia) }\end{array}$ \\
\hline 7 Sprigge $^{10}$ & Motor weakness of $\mathrm{rt}$ arm \\
\hline 8 Sprung (here) & $\begin{array}{l}\text { Weakness of } \mathrm{r} \text { arm; loss of sensation in the } \\
\text { distribution of } C_{8} n \text { and trigeminal } n \text {. palsy }\end{array}$ \\
\hline
\end{tabular}

Legend: $\mathbf{R}$ I = right; $\mathrm{BP}=$ blood pressure; $\mathrm{C}=$ cervical.

succeeded in showing unusually high unilateral cephalad spread ("channeling") of contrast medium on the affected side. ${ }^{14}$ Apostolou et al. have shown that higher levels of epidural anaesthesia were achieved on the dependent side in the lateral decubitus position. ${ }^{15}$ In our first case, withdrawing the catheter one $\mathrm{cm}$ and dosing with additional local anaesthetic resulted in good analgesia and slow regression of the Horner's syndrome. A small change in catheter position may have allowed spread of local anaesthetic through other pathways with more symmetrical diffusion into the epidural tissue planes. 
The volume of the epidural space in pregnant women is decreased, due to partial occlusion of the inferior vena cava at term that diverts the blood through the epidural venous plexus. ${ }^{16}$ This space may become even more reduced during Valsalva manoeuvres, during the second stage of labour when the patient "bears down." This compresses the epidural space, and may induce extensive cephalad spread of the local anaesthetic. ${ }^{8}$ Epidural pressure in the lumbar area increases $10-20 \mathrm{~cm} \mathrm{H}_{2} \mathrm{O}$ with each uterine contraction, ${ }^{3,11}$ and Bromage postulated that high doses of oxytocics given in labour, probably by augmenting this mechanism, may predispose to the induction of Horner's syndrome. ${ }^{17}$ In addition, hyperventilation during labour creates negative intrathoracic pressure which, in conjunction with simultaneously increased intraabdominal pressure in the semi-sitting position during delivery, may theoretically create favourable conditions for cephalad anaesthetic spread. ${ }^{7}$

While Horner's syndrome is a rare, but well known side-effect of lumbar epidural block, trigeminal nerve palsy during epidural anaesthesia has been reported only once. ${ }^{4}$ The fibres of the trigeminal nerve, on approaching its nucleus, divide into short ascending and long descending branches. The long descending branches form the spinal trigeminal tract, which descends from the junction of the pons and medulla to the uppermost segments $\left(\mathrm{C}_{2}\right)$ of the spinal cord, conducting mainly nociception and temperature sensation. In addition, the nucleus of the spinal tract of the trigeminal nerve is continuous caudally with the substantia gelatinosa which is, according to Shigematsu, the logical explanation of the trigeminal nerve palsy after epidural block. ${ }^{4}$ We disagree with this explanation since the spinal nucleus of the trigeminal nerve is a sensory nucleus and, therefore, anaesthetic effects on this structure should not impair motor function. The fibres from the motor nucleus exit the pons and travel with the mandibular division of the trigeminal nerve through the posterior fossa. The blockage of these motor fibres probably has occurred at this level. Initially high epidural spread of local anaesthetic followed by subarachnoid passage and rise to the pontine cistern would be a more plausible explanation for palsy of the muscles of mastication. Bromage showed that the dura is not a functional barrier to the passage of local anaesthestics from the epidural space into the neuraxis and into the subarachnoid space, and that intracranial structures can be affected by excessive doses of local anaesthetic given epidurally. ${ }^{18}$ The proposed routes of local anaesthetic penetration from the epidural space are disussed in detail elsewhere. ${ }^{19}$ The unilateral character of the trigeminal palsy we have described resembles unilateral blocks often seen after epidural anaesthesia in pregnancy. The mecha- nism of asymmetrical spread of epidurally administered local anaesthetic in pregnancy is not well understood.

In summary, two obstetrical patients are presented who showed unusual neurological complications after epidural administration of local anaesthetics. The purpose of this report is to review the theories and explain the development of this rare complication after epidural anaesthesia and to heighten awareness of this event by labour suite personnel. It is important to reassure patients and nursing staff that anisocoria is not a sign of a neurological complication, and to affirm the generally benign course of Homer's syndrome associated with regional anaesthesia for obstetric patients.

\section{References}

I Mohan J, Potter JM. Pupillary constriction and ptosis following caudal epidural analgesia. Anaesthesia 1975; 30: 769-73.

2 Clayton $K C$. The incidence of Horner's syndrome during lumbar extradural for elective Caesarean section and provision of analgesia during labour. Anaesthesia 1983; 8: 583-5.

3 Kepes ER, Martinez LR, Pantuck E, Stark DCC. Horner's syndrome following caudal anesthesia. NY State J Med 1972; 72: 946-7.

4 Shigematsu S, Kobayashi $M$, Ochiai $R$, Nagano $M$. Trigeminal nerve palsy after lumbar epidural anesthesia. Journal of Pain Clinic (Japan) 1984; 5: 37I-4.

5 Chamberlain DP, Chamberlain BDL. Changes in skin temperature of the trunk and their relationship to sympathetic blockade during spinal anesthesia. Anesthesiology 1986; 65: 139-43.

6 Mohan J, Lloyd JW, Ponter JM. Pupillary constriction following extradural analgesia. Injury 1973; 5: 15I-2.

7 Hertz R. Chiovari CA, Marx GF. Delayed Homer's syndrome following obstetric extradural block. Anesth Analg 1980; 59: 299-300.

8 Skaredoff MN, Datta $S$. Horner's syndrome during epidural anaesthesia for elective Caesarean section. Can Anaesth Soc J 1981; 28: 82-5.

9 Schachner SM, Reynolds AC. Homer syndrome during lumbar epidural analgesia for obstetrics. Obstet Gynecol 1982; 59: S31-2.

10 Sprigge JS. Case report: high sympathetic block with ptosis after lumbar epidural analgesia in an obstetric patient. Anaesth Intensive Care 1979; 7: 182-4.

11 Bromage $P R$. Spread of analgesic solutions in the epidural space and their site of action: a statistical study. Br J Anaesth 1962; 34: 161-77.

12 Ray BS, Hinsey JC, Geohegan WA. Preservations of the distribution of the sympathetic nerves to the pupil and 
upper extremity as determined by stimulation of the anterior roots in man. Ann Surg 1943; 118: 647-55.

13 Heavner JR, De Jong $R H$. Lidocaine blocking concentrations for B- and C-nerve fibers. Anesthesiology 1974; 40: 228-33.

14 Adam JF, Fragment W, Castiel J, Lienhart A. Claude Bemard-Horner syndrome and lumbar epidural analgesia. Ann Fr Anesth Reanim 1986; 5: 74-7.

15 Apostolou GA, Zarmakoupis PK, Mastrokostopoulsos $G T$. Spread of epidural anesthesia and the lateral position. Anesth Analg 1981; 60: 584-6.

16 Evans JM, Gauci CA, Warkins $G$. Horner's syndrome as a complication of lumbar epidural block. Anaesthesia 1975; 30: 774-7.

17 Bromage PR. Epidural anesthesia for obstetrics. In: Bromage, PR. Epidural Analgesia. Philadelphia: W.B. Saunders Co., 1978; 588.

18 Bromage PR, Joyal AC, Binney JC. Local anesthetic drugs: penetration from spinal extradural space into the neuraxis. Science 1964; 140: 392-4.

19 Bromage PR. Mechanism of action of extradural analgesia. Br J Anaesth 1975; 47: 199-211.

20 Ough YD, Husain I, Sechzer PH. Horner's syndrome and lumbar epidural anesthesia. Anesthesiology Review 1984; 11: 24-7.

21 Abboud TK, Chen T, Henriksen EH. Horner's syndrome, a rare complication following lumbar epidural block. Anesthesiology Review 1980; 7: 44-5. 